\title{
MAGDALENA JOSEFINA PEÑA MUÑOZ
}

\author{
(22 DE JULIO DE 1939 - 26 DE JUNIO DE 2012)
}

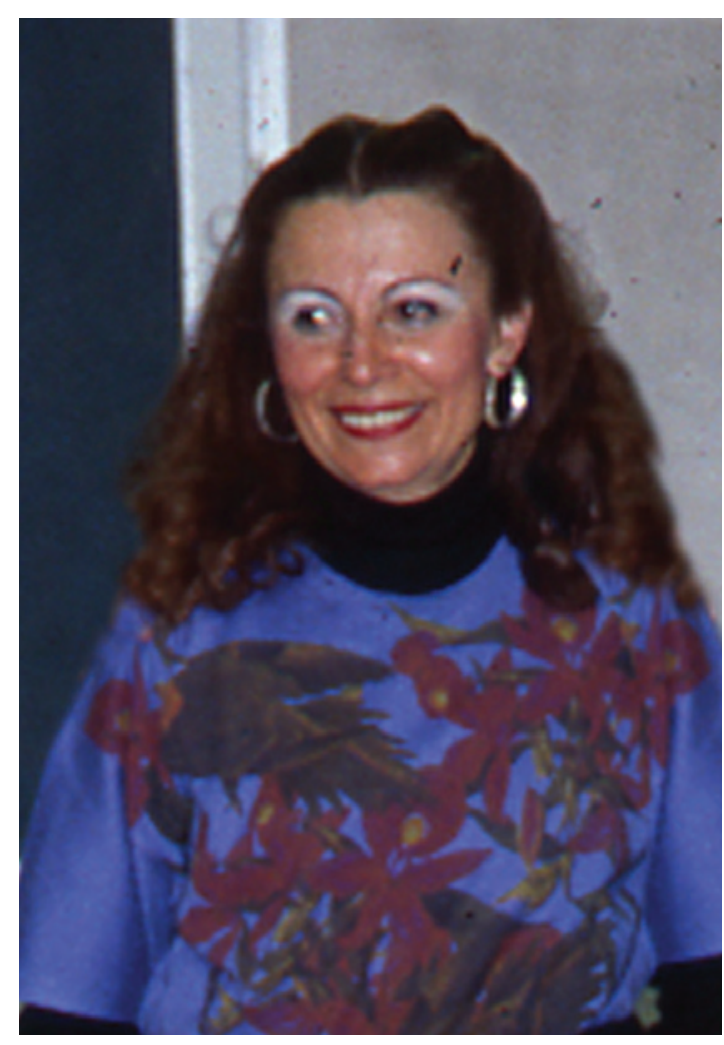

Conocida por sus colegas y amigos como Magda Peña.

Nació en la Ciudad de México el 22 de julio de 1939 y falleció en la misma el 26 de junio de 2012.

Estudió Biología y la Maestría en Ciencias (Biología) en la Facultad de Ciencias de la Universidad Nacional Autónoma de México (UNAM). Realizó una estancia en la Universidad de Harvard de 19681972 para estudiar la taxonomía de los géneros de la Subtribu Laeliinae Bentham (Orchidaceae).

Magda fue una mujer de grandes ímpetus e intereses; por un lado, las ciencias, en especial, la Biología y, por otro, las artes, ya que le apasionaba el dibujo y la pintura, así como la música. Fue profesora del curso de Dibujo Aplicado a la Biología en la Facultad de Ciencias de la UNAM en 1965 y en ese mismo año Ingresó al Jardín Botánico del Instituto de Biología de la misma universidad como dibujante, posteriormente para 1966-1968 continuó su carrera en el propio Jardín como Laboratorista y Técnico Académico antes de partir a Harvard.

A su regreso a México en 1972 se reintegró nuevamente al Jardín Botánico dedicándose de lleno al cultivo, propagación y manutención de la colección de orquídeas, que había estado hasta ese entonces bajo el cuidado de Otto Nagel. Ese mismo año, bajo su dirección, la Colección de Orquídeas participó en la V Exposición Nacional de Orquídeas organizada por la Asociación Mexicana de Orquideología, obteniendo el primer lugar con la especie Stanhopea oculata. Para 1973, participó nuevamente en la VI exposición y volvió a obtener el primer lugar, en este caso, con la especie Chondrorhyncha discolor.

Estas experiencias, entre otras, en conjunción con su interés por otras manifestaciones de la cultura y su estancia en el extranjero le brindaron una visión en el campo de la Divulgación de la Ciencia donde vislumbró una ventana de oportunidad en nuestro país que, para esa época, era poco común entre los investigadores del área de ciencias básicas. En 1979 fue nombrada directora del Jardín Botánico del Instituto de Biología de la UNAM, donde impulsó ampliamente la Divulgación y a todos los técnicos académicos que en ese entonces ahí laborábamos nos envió a capacitar a diferentes Jardines Botánicos del mundo, en variadas especialidades, incluyendo substancialmente la Divulgación de la Ciencia. Para algunos de nosotros, esta oportunidad nos abrió un mundo de oportunidades, nos amplió la visión y permitió generar programas mejor fundamentados, más profesionales y más exitosos. Fue durante su gestión como directora cuando se inicia la tradición del Calendario del Jardín Botánico, que mostró durante más de una década la visión del artista sobre diferentes grupos de plantas y proyectos ahí realizados. Este calendario evolucionó para convertirse hoy en día en el calendario del Instituto de Biología de la UNAM, que ha sido embajador de nuestra institución en muchos países del mundo. 
Apoyada por su prestancia e inquisitiva personalidad, incursionó desde el Jardín Botánico en el campo de la Divulgación, con la elaboración de audiovisuales como: Orquídeas... Arte, Ciencia y tecnología; Agua... Forma ecológica; Orquídeas... Mística y erótica, entre otros. Promovió también la participación del Jardín Botánico en exposiciones internacionales como "Les Floralies" de Montreal, 1980 y exposiciones nacionales en colaboración con otras dependencias de la UNAM, además de promover desde el jardín botánico la organización de diferentes ciclos de conferencias dirigidos a todo público, Seminarios y exposiciones sobre Botánica.

Por otro lado, durante su gestión trabajó arduamente en la reorganización, inventario y catalogación de las colecciones de plantas vivas, y con el apoyo y visión del Director del Instituto de Biología, el Dr. José Sarukhán, implementó la formación de nuevos grupos de investigación organizando así la Unidad de Recursos Genéticos Vegetales (UNIRGEN). Formó personal especializado en el campo de la Orquideología, dirigió varias tesis y motivó a muchas personas sobre la importancia de la Divulgación de la Ciencia, desde donde siempre es recordada.

Entre sus publicaciones en el campo de su especialidad destacan: "El uso de las orquídeas en México desde la época prehispánica hasta nuestros días", en colaboración con María del Rosario García Peña (1981); "Aspectos taxonómicos de Habenaria strictissima Reichb. F." (1984); "Consideraciones Fenológicas, Morfológicas y de Germinación in vitro", en colaboración con Víctor Manuel Chávez (1986) y muy especialmente el tratamiento de la familia Orchidaceae en la Flora Fanerogámica del Valle de México de los doctores Rzedowski (2001), referencia obligada para las personas que estudiamos las plantas de la cuenca de México.

\section{Las Sociedades científicas en su vida}

A su regreso de los Estados Unidos, se reintegró activamente a la Sociedad Botánica de México donde fungió como vicepresidenta de 1974-1975 y como presidenta para 1976-1977, desde donde promovió la divulgación y la labor ya tradicional de la Sociedad de aquel entonces, de motivar e invitar a los aficionados de los diferentes campos de la botánica a participar en diversas actividades que la Sociedad organizaba con este fin. Así continuó con las ilustrativas y divertidas excursiones que se realizaban bajo la guía de botánicos en diferentes campos, en las cuales los expertos convivían con todos los participantes de forma amigable y divertida, por lo que muchos de los estudiantes jóvenes de aquel entonces que participábamos asiduamente en estas actividades nos motivamos, orientamos y decidimos nuestro futuro académico.

Siempre interesada en las Sociedades científicas, apoyó la consolidación de la Asociación Mexicana de Jardines Botánicos, de la que fungió como presidenta del año 1988-1990. Durante su gestión, convocó a un concurso para la elaboración del logotipo de esa Asociación, que hasta ahora la identifica; también organizó una encuesta para escoger el nombre de un boletín informativo que desde su punto de vista lo visualizó como:

“... medio informativo que recogerá la dinámica de cada jardín en los aspectos de Investigación, Conservación, Enseñanza y Difusión. Así como inquietudes, opiniones y noticias".

En la presentación del primer número considera que:

"Los Jardines Botánicos de México son testimonio, en el pasado de la riqueza del manto vegetal; en el presente de la necesidad de preservarlo; hacia el futuro sus restauradores. Y visualiza a la Asociación Mexicana de Jardines Botánicos, como un vínculo de ideales compartidos, que se propone a través de diferentes mecanismos, preservar, propagar y restaurar este rubro del patrimonio nacional" <www.amjb.unam.mx/boletin_amaranto_anterior.html> 
Fue así como organizó la publicación de los tres primeros números de este boletín nombrado ya para entonces "Amaranto" con dieciséis fascículos.

Como hemos podido constatar las acciones, ideales y aspiraciones de Magda Peña han contribuido a la Orquideología, los Jardines Botánicos de México y a las Asociaciones y Sociedades Científicas en las que ella participó, por lo cual la familia académica del Jardín Botánico del Instituto de Biología de la UNAM la recordamos con gran cariño y reconocemos que sus aportaciones e ideas, realizadas principalmente durante su gestión como directora, han dejado huella en nuestra institución y para la Asociación Mexicana de jardines Botánicos han sido un pilar sobre el cual se han podido construir nuevos esfuerzos, que la hacen una Asociación seria, vigorosa y reconocida en el resto del mundo como vanguardista.

La sobreviven sus tres hijos: Mario, Raúl y Leonardo y sus dos nietos Sebastián y Monserrat.

\section{Edelmira Linares}

Jardín Botánico,

Instituto de Biología,

Universidad Nacional Autónoma de México 